\title{
El misterio del oro Dánae y la lluvia dorada, entre alquimia y ciencia económica
}

\author{
The Mystery of Gold \\ Danae and the Golden Rain, amidst Alchemy and Economic Science
}

\section{Catalina Aldama \\ cataldama@gmail.com \\ Instituto de Altos Estudios Sociales. Universidad Nacional de San Martín. Argentina}

Recibido: $11 / 11 / 2019$ Aceptado: $16 / 3 / 2020$

\begin{abstract}
Resumen
Entre los siglos XVI y XVII, en Europa continental, proliferaron pinturas y grabados dedicados al episodio mítico de Dánae y la lluvia dorada. El elemento que distingue la escena de Dánae de otros desnudos mitológicos es el oro, el cual aparece como una sustancia corruptora. A partir de la particular pintura realizada por Hendrik Goltzius sobre este tema, el propósito de este trabajo es investigar la manera en la que aparece representado el oro en algunos de los óleos del período. Indagaremos acerca del vínculo de estas imágenes con la curiosidad propia de la época por desentrañar el misterio del metal. Desde un tratado alquímico hasta un texto protoeconómico, entre la magia y la ciencia, encontraremos a Dánae siendo evocada para esbozar explicaciones sobre el poder del oro.
\end{abstract}

\section{Palabras clave}

Dánae; desnudos mitológicos; historia del arte; historia del pensamiento económico; alquimia

\begin{abstract}
Between the XVI and the XVII centuries, in continental Europe, there was a proliferation of paintings, engravings, frescoes and prints dedicated to the mythical episode of Danae and the golden rain. The distinctive element of Danae's scene, in comparison to other mythological nudes, is gold, which appears as a corrupting substance. Taking Hendrik Goltzius' painting on the subject as a starting point, the purpose of this article is to investigate the way in which gold is represented in some of the paintings of the period. We will explore the link of these images with the curiosity of the time to unravel the mystery of this metal. From an alchemical treatise to an economic text, between magic and science, we will find Danae being evoked in order to explain the power of gold.
\end{abstract}

\section{Keywords}

Danae; mythological nudes; art history; history of economic thought; alchemy 
1 Ver Biblioteca mitológica [siglo I-II d. C.] (1950), de Apolodoro, y Las Metamorfosis [8 d. C.] (2012), de Publio Ovidio Nasón.
La versión del mito de Dánae que se ha propagado desde la Antigua Grecia a la cultura occidental se puede resumir, de manera esquemática, como se plantea a continuación. ${ }^{1}$ Acrisio, el rey de Argos, preocupado por no tener descendencia masculina, consulta al oráculo, quien le anuncia que su nieto lo matará. Alertado por esta visión, recluye a su hija Dánae en una torre para evitar que jamás conciba un hijo. Sin embargo, Zeus encuentra a la bella joven confinada $y$, transmutado en una lluvia áurea, cae sobre ella, engendrando así a Perseo. Enterado de este nacimiento, Acrisio encierra a Dánae con su hijo en un cofre y los arroja al mar. Ambos sobreviven y recalan en la isla de Sérifos, donde Dictis los acoge. Perseo, el joven semidiós, se destaca por dos hazañas: la decapitación de la Medusa y el rescate de Andrómeda. Cuando finalmente retorna a sus tierras de origen, mata por accidente a su abuelo en los juegos de un reino cercano y se convierte así en el flamante gobernante de Argos.

Una de las escenas más representadas del relato es el episodio de Dánae y la lluvia dorada. En la mayoría de las representaciones clásicas - que aparecen en vasijas, azulejos, monedas- se observa una mujer semidesnuda, sentada o yaciente, que alza su túnica para recibir las gotas que caen sobre ella. En algunos casos, las imágenes son más explícitas: muestran un contenido casi pornográfico, en consonancia con citas literarias de la época que, tal como señala Cathy Santore (1991), identifican a Dánae como una mujer corrompida por el oro, más que poseída por un Dios.

Por su parte, durante el período medieval —e incluso hasta el siglo $\mathrm{XV}$ - aparece un nuevo repertorio figurativo para representar la escena de la lluvia dorada. Se trata de ilustraciones que acompañan a ciertos textos, que esencialmente reinterpretan los mitos antiguos con fines moralizantes. De manera esquemática, las imágenes muestran a una joven en lo alto de una torre recibiendo el baño de una lluvia. Tal como explica Erwin Panofsky (en Sluijter, 1999), en este tipo de tradición iconográfica la escena en cuestión aparece como una alegoría de la castidad (la torre se interpreta como un símbolo de ello). Incluso, autores posteriores a Panofsky afirman que estas representaciones plantean a Dánae como una prefiguración de la Virgen María y de la Inmaculada Concepción (Sluijter, 1999).

Si bien el episodio de Dánae y la lluvia dorada sobrevivió a la Antigüedad y atravesó la Edad Media a través de representaciones 
visuales y menciones en la literatura, no fue hasta el año 1527, con la Dánae de Jan Gossaert (Mabuse, 1478-1532) [Figura 1], que se convirtió en un tema de gran difusión en la pintura.

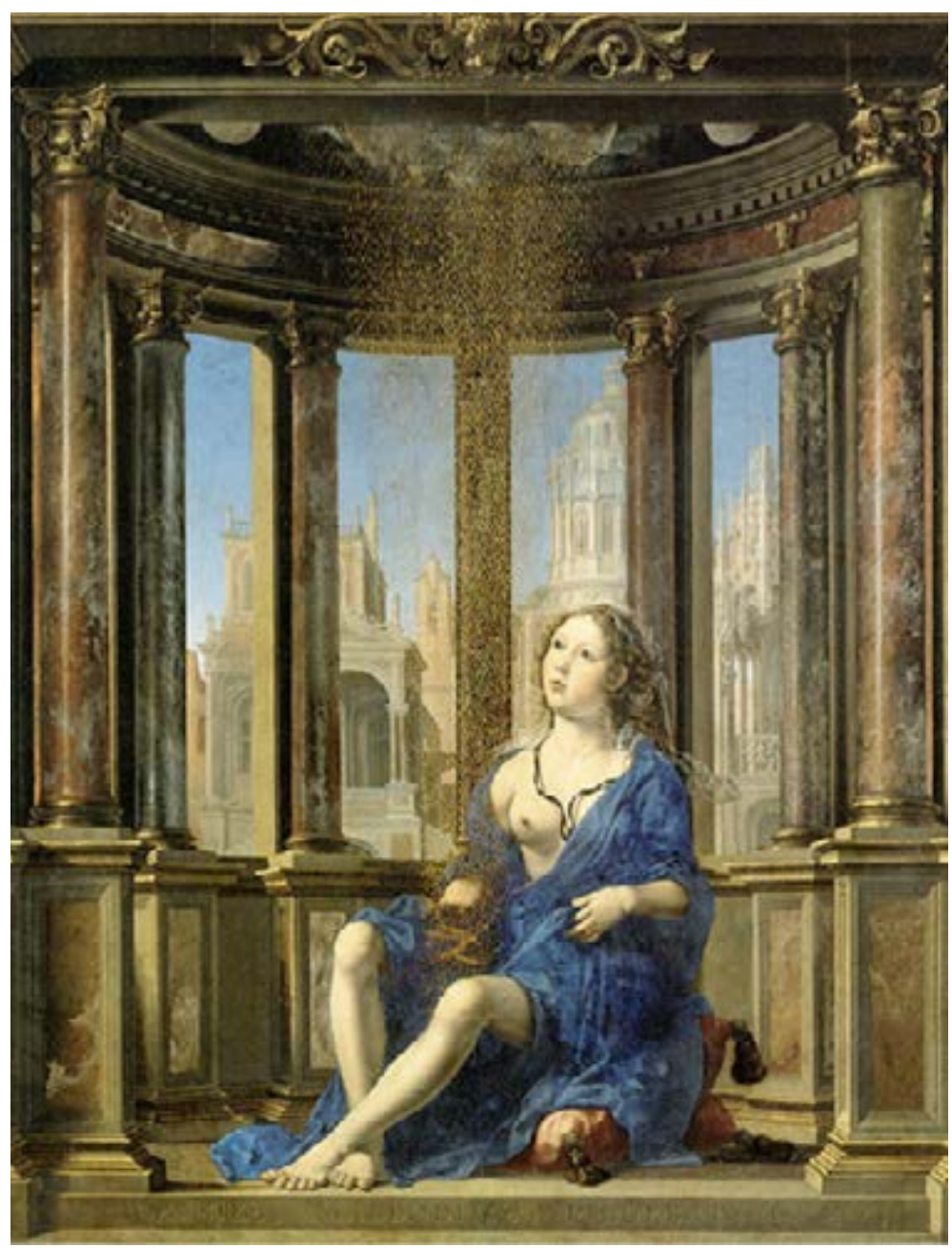

Figura 1. Dánae (1527), de Jan Gossaert van Mabuse. Alte Pinakothek, Múnich

Apartirdela obrade Mabuse se observauna proliferación de pinturas y de grabados dedicados a representar esta escena en Europa continental. En efecto, se suceden las versiones de Antonio Allegri da Correggio (1531), Tiziano Vecellio (al menos seis ejemplares que salen de su taller entre 1545 y 1565), Tintoretto (1570), Joachim Wtewael (entre 1595 y 1605), Hendrik Goltzius (1603), 
Artemisia y Orazio Gentileschi (1612 y 1621, respectivamente), y Rembrandt Harmenszoon van Rijn (1636), entre las de mayor notoriedad hasta el siglo XVII.

La Dánae de Gossaert se sitúa como un punto de inflexión en la fórmula representativa de este mito. La pintura recoge interpretaciones y tradiciones iconográficas anteriores, cuya síntesis resulta en una imagen ambivalente que se encuentra a mitad de camino entre la pudicia y la sensualidad del personaje femenino (Sluijter, 1999). Las obras dedicadas a Dánae posteriores son menos ambiguas en este sentido, en tanto, se encuentran de manera más evidente, cargadas de erotismo. Sin embargo, podríamos decir que la ambivalencia de esta forma representativa se traslada a otro aspecto de la imagen: la naturaleza del encuentro representado se halla en tensión entre la burda transacción mercantil y la unión mística con un dios.

Por un lado, las obras mencionadas comparten ciertas características: en todos los casos se trata de una escena de interior, más precisamente, la acción se sitúa en una recámara; la composición se encuentra centrada en Dánae que, de manera inequívoca, aparece desnuda, yaciente en una cama o sillón. En la mayoría de las versiones consideradas la figura está acompañada por un cupido, o bien, por un personaje femenino añoso, que suele tener los atributos de una alcahueta o dama de compañía; y, por último, el elemento que distingue a Dánae y la lluvia dorada de otros desnudos mitológicos, tan asiduos durante la época: la ineludible presencia del oro. Este se encuentra en las monedas que caen como lluvia, en los objetos dorados que se acumulan en la alcoba, en las joyas que luce la doncella sobre su cuerpo, en los detalles lujosos de la estancia: telas finas, un mobiliario majestuoso, etcétera.

Por el otro lado, en muchas de estas obras, más allá de la presencia del oro, no se observa ninguna referencia directa a la divinidad que consuma este acto sobre Dánae. Solo en algunas de las versiones aparece Zeus antropomorfizado -como en la obra de Wtewael, donde un hombre se suspende sobre la joven asustada seguido por un águila - o alguno de sus atributos, como en el caso de una de las versiones de Tiziano - la que pertenece a la colección Wellington[Figura 2] y la Dánae de Goltzius, en las que se incorpora a la composición un águila y un rayo. Aún cuando esta simbología se encuentra ausente, se advierte la atmósfera mística que rodea la escena. Es evidente que un evento extraordinario está sucediendo. 


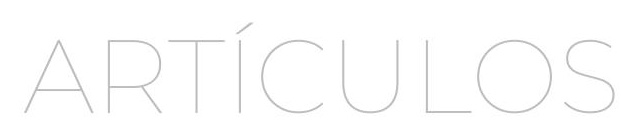

Se observa un clima de tormenta por las ventanas de la recámara que aluden a los rayos del dios griego como en el caso de las versiones de Tiziano y la de Tintoretto o un particular uso de la luz y del color que aporta un ambiente brumoso, como se aprecia en la versión de Rembrandt.

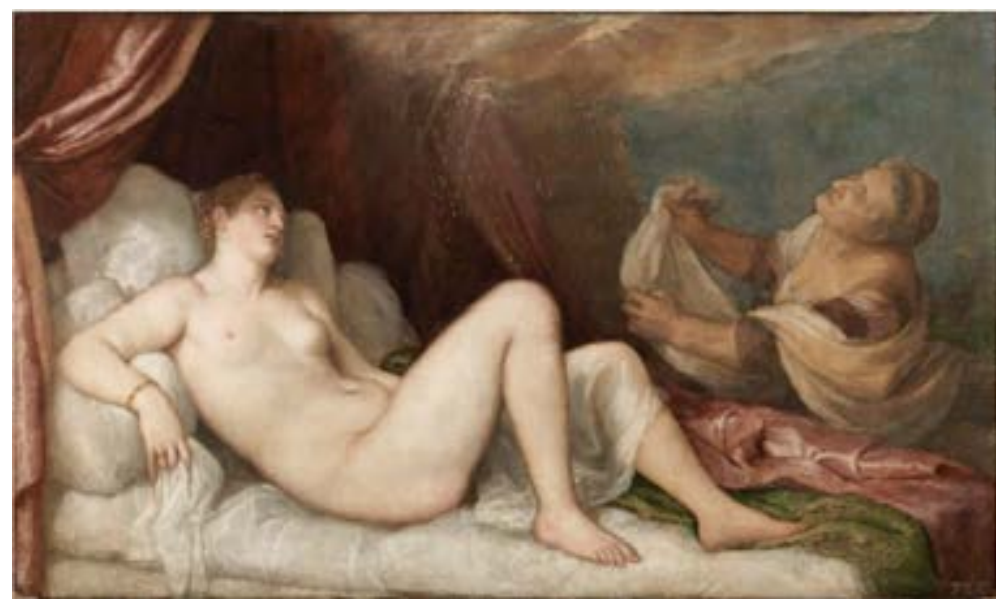

Figura 2. Dánae (1553), de Tiziano Vecellio. Apsley House, Colección Wellington, Londres

2 Richard Seaford (2004) señala que, aunque el dinero moderno puede ser considerado la antítesis de lo sagrado por su "promiscua intercambiabilidad», también puede asimilarse a lo divino, pues comparten ciertas cualidades: la permanencia, la unicidad, la trascendencia y el poder (p. 2)
Por su parte, a pesar de la atmósfera cargada que se vislumbra en muchas de estas versiones, resulta difícil asociar el oro y su representación con la presencia divina. El oro aparece como un objeto tangible en la forma de monedas, es decir, la forma material que toma la mercancía dineraria, lo cual implica una lectura racional del mito que acerca el relato a los sucesos de la realidad operativa del público de la época. Esta fórmula representativa retoma la antigua narrativa antes mencionada en la que Dánae es considerada como una cortesana que vende su cuerpo por dinero (Santore, 1991). De esta manera, la interpretación del mito traslada la figura de poder y posesión sobre el cuerpo y la voluntad de la mujer, del dios al dinero. ${ }^{2}$ Una de las cuestiones que revela la escena es la inquietud que produce lo que en definitiva podríamos reducir a un intercambio mercantil y, particularmente, el profundo misterio que despierta el poder del dinero, inevitablemente identificado con el oro. Como un acto de magia, caen monedas del cielo, la dama de compañía se apura a recogerlas y se consuma la entrega: yace la mujer desnuda y dispuesta. ¿Qué tiene el oro que ostenta tal poder? 
En el tercer capítulo de El capital [1867] (2011), titulado «El dinero, o la circulación de mercancías», Karl Marx señala: «A medida que se expande la circulación mercantil se acrecienta el poder del dinero, la forma siempre pronta, absolutamente social de la riqueza». $Y$ agrega: "Todo se vuelve venal y adquirible... no resisten a esta alquimia ni siquiera los huesos de los santos" (Marx, [1867] 2011, pp. 160-161). Asimismo, el filósofo cita un pasaje de la obra de teatro Timón de Atenas, de William Shakespeare, que resulta por demás elocuente:

¿Oro? ¿Oro cobrizo, brillante, precioso?... En profusión, habrá de tornar blanco al negro, hermoso al feo; lo falso, verdadero; noble al ruin; mozo al viejo, y al cobarde, valeroso. ¡Oh, dioses! ¿Por qué, qué es esto? Porque él apartará de vuestro lado sacerdotes y servidores; retirará la almohada de debajo de la cabeza de los hombres más robustos: este amarillo esclavo va a unir religiones y escindirlas, enaltecer a los malditos, hacer que se adore a la lepra blanquecina, sentar a los ladrones en los escaños del senado y otorgarles títulos, genuflexiones y beneplácitos; él es el que procura nuevas nupcias a la viuda achacosa... Vamos, tú, cieno maldito, puta común del género humano (Shakespeare en Marx, [1867] 2011, p. 161).

Madlyn Millner Kahr (1978) señala que es justamente la representación de Dánae como una mujer venal lo que alimentó la frecuente aparición del mito en pinturas, en grabados, en dibujos, en ilustraciones y en textos literarios. No es posible, entonces, eludir el vínculo entre el uso profuso que se hizo de la escena de Dánae y la lluvia dorada en el arte y en la literatura durante los siglos XV, XVI y XVII, y la turbación que provocó el oro en ese mismo período, por la función central que pasó a ocupar en la vida diaria de los hombres.

Podemos señalar dos ámbitos de conocimiento que se dedicaron a desentrañar, desde distintas perspectivas, el misterio del oro y que tomaron relevancia durante este período: la ciencia económica y la alquimia. En efecto, es durante esta época que la historia del pensamiento económico ubica los primeros esbozos de teoría económica, es decir, las incipientes explicaciones -emancipadas de la doctrina religiosa y de la moral-acerca de cómo se determinan, se mueven y se transforman los fenómenos económicos, como la relación mercantil, el precio y la moneda, entre otros (Aldama y otros, 2012). En cuanto a la alquimia, a pesar de tratarse de un saber atávico, es durante el siglo XVI cuando despierta un gran interés en las cortes europeas, y se conforman círculos de alquimistas cuya labor es promocionada por reyes y por príncipes. 
3 Ver Las ciudades de la Edad Media [1926] (2011), de Henri Pirenne; A History of Economic Thought [Historia del Pensamiento Económico] [1929] (1989), de Isaac Ilych Rubin, y Estudio de la mentalidad burguesa [1987] (2010), de José Luis Romero.
4 Ver "Las transformaciones de las representaciones del mundo desde el tránsito de la Edad Media al Capitalismo Comercial como concepto económico» (2012), de Catalina Aldama y otros, e «Investigación sobre la transición entre las doctrinas mercantilistas y el nacimiento de la Economía Política. Un análisis de los aportes de Thomas Mun, James Steuart y David Hume» (2018), de Pilar Piqué y otros.

\section{Dánae y el misterio del dinero}

Desde una perspectiva económica, los siglos XIV, XV y XVI son una etapa de transición significativa en Europa Occidental: se consolida la mercancía como una relación social general, que organiza la producción y la reproducción de la sociedad; la ciudad pasa a ser el territorio en el que se desarrolla la nueva vida del hombre que vive del comercio y sus actividades asociadas; y se conforma una nueva clase social de comerciantes urbanos que comienza a tener poder económico y cierto poder político a través de las alianzas que teje con la monarquía. Ingresa al continente europeo una cantidad de metales preciosos (oro y plata) sin precedentes, producto del saqueo de América, lo cual fomenta el comercio, a la vez que provoca nuevos fenómenos como el aumento generalizado de los precios. ${ }^{3}$

A medida que avanza la mercancía como relación social general y que una mayor parte de la población se ve incorporada a una organización de la reproducción social mediada por la relación mercantil, el oro - que hoy sabemos que es la manifestación más elemental del dinero, pero también del capital- pasa a tener una función fundamental en la realidad operativa de las personas. La ciencia económica no puede sino partir de las manifestaciones del objeto, es decir, del ámbito en el cual se presentan los fenómenos, que no es otro que la circulación mercantil. El dinero y el capital se fusionan con el oro y es acerca del oro, entonces, sobre lo que escribirán estos incipientes teóricos.

Adam Smith [1776] (1999) llama mercantilistas a esta variedad de autores que, esparcidos a lo largo de tres siglos en distintas naciones europeas, dedicaron algún texto a estudiar ciertos fenómenos económicos. Su denominación surge de la característica que los aúna e identifica: la noción de que los metales preciosos constituyen la riqueza y que, por ende, una nación más rica es aquella que puede retener la mayor cantidad de oro y plata hacia dentro de sus fronteras. La indiferenciación entre oro y riqueza típicamente mercantilista, va de la mano con la indistinción entre el oro y la moneda (signo de valor que surge como consecuencia de la función del dinero como medio de circulación), la moneda y el dinero, y el dinero y el capital. ${ }^{4}$ En este sentido, los mercantilistas se preocuparon por la merma en el valor de la moneda que surge de la pérdida de metálico, a la vez que recomendaron retener los metales preciosos, incluso en detrimento de la propia actividad comercial. De este modo, concibieron el acaparamiento de plata y oro como un fin en sí mismo. 


\section{ARTICULOS}

Entre los autores que se inscriben en la doctrina mercantilista, se encuentra Bernardo Davanzati (1529-1606), un comerciante, escritor y teórico florentino. En 1588 publicó un texto relevante para la historia del pensamiento económico, titulado Lezione delle monete. El texto, que hoy situamos en los albores de la ciencia económica, comienza con un retrato de las características de los metales preciosos que dista de manera significativa de lo que en la actualidad entenderíamos como un discurso científico.

En efecto, Davanzati afirma al inicio que el sol y el calor interno, casi rezumando, hacen extraer los mejores jugos y sustancias de las vísceras de la tierra. Estos se filtran por sus venas y minas $y$, al congelarse y endurecerse con el tiempo, devienen metales, de los cuales, los más perfectos y raros son el oro y la plata (Davanzati, [1588] 1803). Esta descripción por momentos se ubica en el ámbito de lo maravilloso, a la vez que recoge ciertas referencias de la práctica de la alquimia, por ejemplo, al utilizar la imagen de la tierra destilando ciertos líquidos que luego, al solidificarse, se convierten en oro y plata.

Davanzati continúa con su discurso sobre la moneda y comenta que el oro y la plata no sirven en su forma natural a los hombres, pero que los hombres igualaron el valor de los metales preciosos al de todas las cosas, para convertirlos en el precio y medida de todo aquello que existe en el mundo. De esta manera, el oro devino la segunda causa de una vida feliz ya que, por medio de él, se puede obtener todo aquello necesario para vivir. Algunos hombres hicieron del oro su Dios, al ver al metal realizar hazañas imposibles, clama el autor. En este contexto hace su aparición Dánae y la lluvia dorada: «No hay roca tan fuerte que resista un burro cargado de oro, dice el rey guerrero, que sabía qué decir; no son otros que los milagros del oro, como lo denotan la fábula de Danae volgatissima, y aquella de

5 «Rocca non è sì forte, che non la sforzi un asinello carico d'oro, dise quel re guerriero, che sapeva che dirsi; nè altro, che i miracoli che fa l'oro, denotan la favola di Danae volgatissima, e quella di Gige pastore di Lidia» (Davanzati [1588] 1803, p. 21). Itálica y traducción de la autora del artículo.

De este modo, el mito de Dánae se presenta como uno de los milagros del oro. Aquí también se reproduce el discurso, que carga ciertas reminiscencias mágicas, de que el oro es la materia que logra aquello irrealizable. Nada se le resiste al oro, ni siquiera una joven bella, lo cual enfatiza la omnipotencia del metal. Sin embargo, también plantea que el poder que posee el oro lo tiene, en tanto y en cuanto, el hombre lo ha hecho a la medida de todas las cosas. Es decir, es el hombre quien ha hecho del oro el equivalente general. Davanzati comprende el poder que emana del oro e intuye que la fuente de dicho poder se encuentra vinculado al hecho de que el oro es la mercancía dineraria. 
Sin embargo, el autor no puede aún explicar de qué manera el dinero es un desprendimiento inevitable del desarrollo de la mercancía como relación social general y de ahí las rémoras mágicas y la asociación de su teoría sobre el dinero con el mito de Dánae.

\section{La Dánae de Hendrick Goltzius y la incorporación de Mercurio}

La Dánae que Hendrik Goltzius (1558-1617) pintó en 1603 [Figura 3] es primordialmente un desnudo femenino - nude-, con todas las características que John Berger (2000) le atribuye a este género de la pintura europea al óleo. La joven se encuentra en el centro de la composición, su cuerpo yace desnudo, disponible para ser observado. Es el único personaje que tiene los ojos cerrados y presenta una actitud pasiva, mientras que todas las demás figuras que la rodean están despiertas y en actividad. Tal como ya hemos mencionado, lo que distingue este tema de otros que también han sido aprovechados para pintar desnudos, es la presencia del oro, que en este caso es prolífica. Se observan monedas desparramadas en el suelo de la habitación, un cofre entreabierto con monedas y cadenas doradas, y una copa de oro con tapador muy trabajada. A su vez, uno de los Cupidos lleva una bolsa de dinero atestada de oro y la dama de compañía - un personaje usual en estas representaciones- porta una fuente dorada, mientras toca el hombro de la Dánae durmiente. Detrás de ellas, se observa un águila en pleno vuelo, que sostiene un rayo en una de sus garras -ambos símbolos de Júpiter-y está rodeada de unas nubes de tormenta de las cuales emanan partículas doradas. Para Eric Jan Sluijter (1999) es evidente que la versión de Goltzius «[...] cuenta una historia de sexo y dinero» (p. 31).

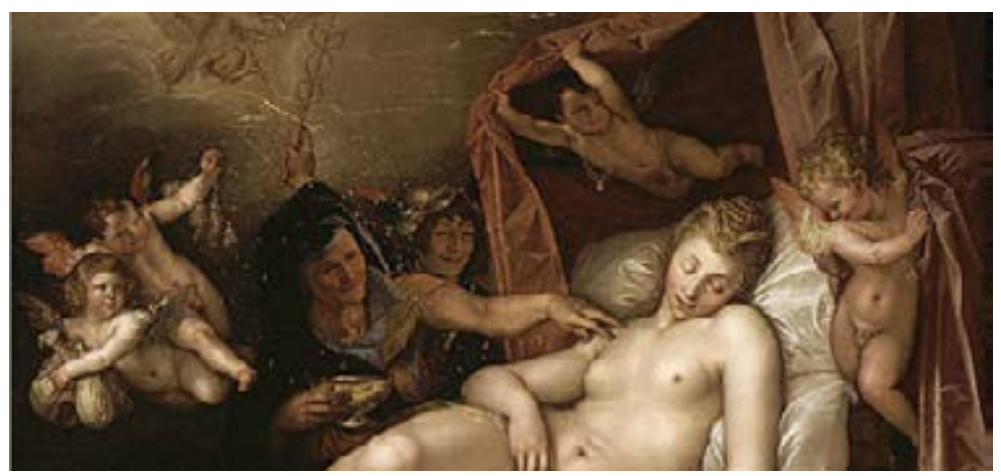

Figura 3. Dánae durmiente siendo preparada para recibir a Júpiter (1603), de Hendrik Goltzius. Los Angeles County Museum of Art, Los Ángeles 
6 Eric Jan Sluijter realiza esta mención en «Emulating sensual beauty: Representations of Danaë from Gossaert to Rembrandt [Emulando la belleza sensual: Representaciones de Dánae, desde Gossaert hasta Rembrandt]» (1999). También se pueden consultar los significados atribuidos a Mercurio (Hermes) en Dictionnaire des symboles: Mythes, rêves, coutumes, gestes, formes, figures, couleurs, nombres [Diccionario de símbolos: mitos, sueños, costumbres, gestos, formas, figuras, colores, números] (1982), de Jean Chevalier y Alain Gheerbrant.
La mayor particularidad de la versión de Goltzius es la inédita presencia de Mercurio. Al costado de la dama de compañía se observa un joven con los atributos del dios: el gorro alado y el caduceo en su mano derecha. No hay ninguna fuente literaria que dé cuenta de su presencia en el suceso y, en este sentido, se entiende que la aparición en la escena ha sido particularmente elegida por el artista. Siendo Mercurio hijo de Júpiter y heraldo de los dioses, su presencia podría relacionarse con su función de mensajero, vínculo entre el mundo de los dioses y el de los mortales. En esta escena, entonces, anunciaría la inminente llegada de Júpiter. Ahora bien, podría tratarse también que el joven dios fuera un símbolo del comercio, otro atributo habitual de Mercurio. ${ }^{6}$ De ser el caso, la referencia a la mercancía aparece aquí nuevamente y de manera explícita. No es solo el oro, en su función dineraria, que logra seducir a la joven Dánae, sino que además se agrega la aparición de un dios que posee las aptitudes de un comerciante: es astuto y elocuente, versado en la práctica del convencimiento.

Aquí podríamos detenernos en la ambigüedad de la presencia de este personaje. Por un lado, Mercurio aparece para comunicar un mensaje que llega sin mediaciones, imponiéndose la voluntad del dios sobre la de Dánae. Por el otro, se debe considerar el vínculo de Mercurio con la negociación. En este segundo aspecto, la figura se aliaría con el intercambio mercantil: no se impone una voluntad sobre la otra, sino que se convence a la joven de que voluntariamente se ofrezca al dios. No es insólito pensar que para los hombres del seicento, el oro se les representara con esta ambivalencia: como un Dios Todopoderoso y, a la vez, como un instrumento para el intercambio mercantil, un tipo de transacción voluntaria que se supone entre dos partes libres e iguales.

\section{La alquimia y el misterio del oro}

Otra interpretación inexplorada de la presencia de Mercurio en la pintura de Dánae realizada por Goltzius se relaciona con la alquimia. En efecto, existen distintos indicios que vinculan al artista con las prácticas alquímicas. Testimonios de la época resaltan su fascinación con este saber: su biógrafo y amigo Karel van Mander hace mención a su investigación alquímica para "purificar pigmentos»; el poeta Constantijn Huygens en su autobiografía inconclusa describe la curiosidad de Goltzius por estos temas e, incluso, existen documentos del año 1605 que lo 


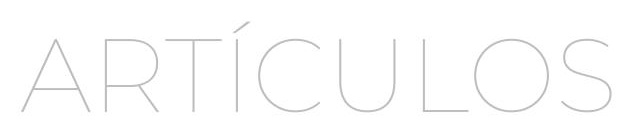

vinculan con el alquimista Leonard Engelbrecht, cuyo esfuerzo por producir oro habría sido apoyado por el artista (Melion, 1992). A su vez, se debe tener en cuenta un retrato de Goltzius producido póstumamente por el grabador Jonas Suyderhoef (1613-1686), en el que se observa un elemento que remite a la alquimia [Figura 4]. En los bordes de la composición se reconocen dos caduceos en las esquinas superiores, a la vez que se puede leer el emblema del artista $E r$ boven golt en el centro arriba. Además, se agrega como particularidad de esta versión, dos vasos de destilación a cada lado, instrumentos relacionados con la práctica alquímica.

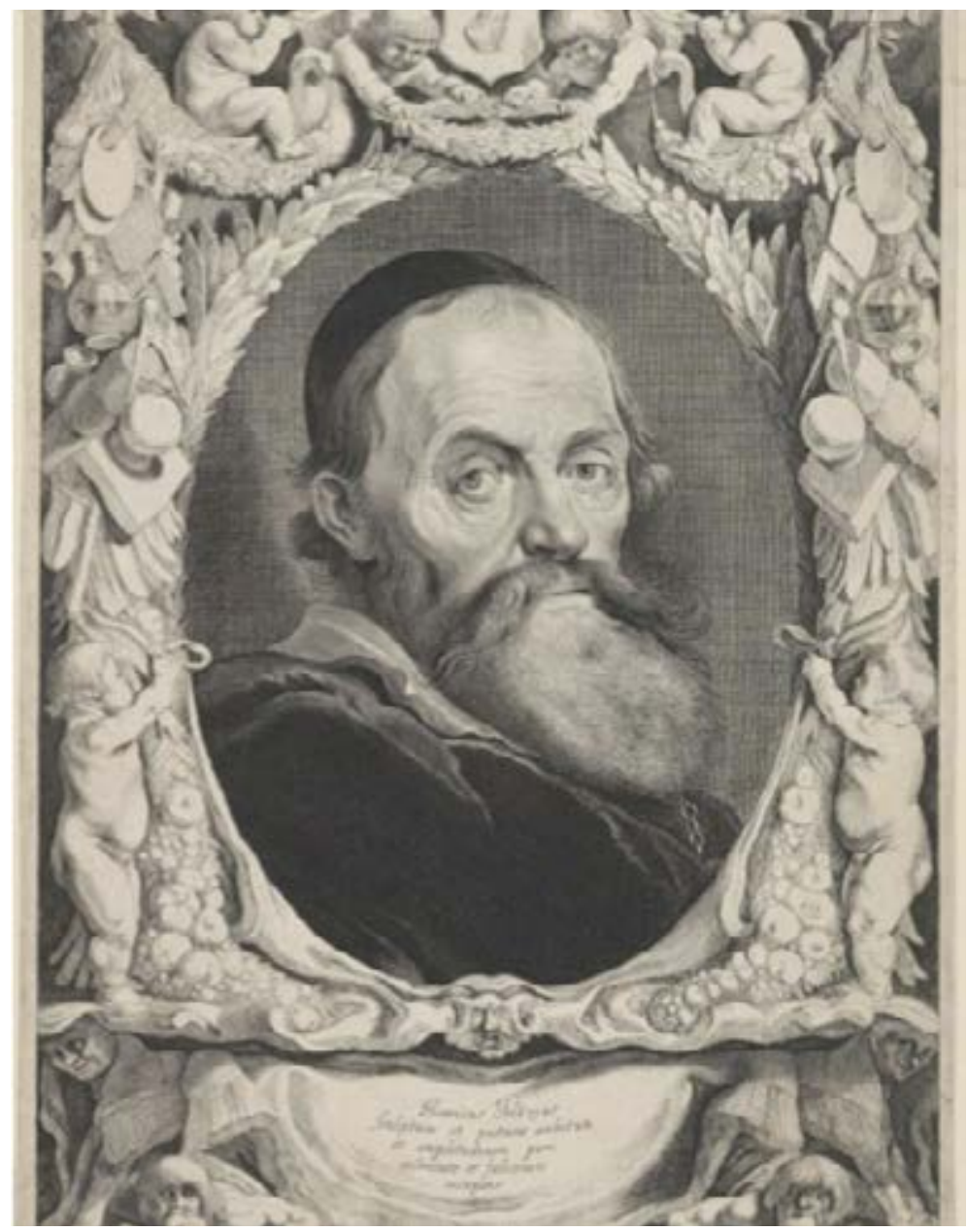

Figura 4. Retrato de Hendrik Goltzius (1649), de Jonas Suyderhoef. Museo Boymans van Beuningen, Róterdam 
En virtud de esta conexión del artista con la alquimia, se puede aventurar una nueva interpretación acerca de la presencia de Mercurio en la representación de Dánae. En efecto, para la alquimia occidental sintetizada en la gran obra (Opus Magnum) el proceso por medio del cual se llega a la piedra filosofal- todo se compone de los tres principios. el azufre, el mercurio y la sal. El azufre y el mercurio se presentan de manera antitética, puesto que el azufre es el elemento activo, asimilado con lo masculino y con el fuego, mientras que al mercurio se lo considera el elemento pasivo, asociado a lo femenino y al agua. Por su parte, la sal es el elemento neutral, el equilibrio entre el azufre y el mercurio. El mercurio, entonces, es el ambiente húmedo en el que, con la acción del azufre, se da paso a la creación de una nueva sustancia. Es, en efecto, la reunión subterránea entre el mercurio (la semilla femenina) y el azufre (la potencia de lo masculino), la que produce los metales (Chevalier \& Gheerbrant, 1982).

En este sentido, la presencia de Mercurio en la escena de Dánae podría aludir al acto sexual y a la gestación. La figura del águila se cierne sobre la escena mientras Júpiter desciende con un rayo en sus garras, para actuar sobre Dánae, quien aún yace dormida. El juego de oposiciones complementarias entre el elemento activo y el pasivo, el masculino y el femenino, es notorio. Producto de este encuentro será concebida la nueva criatura: Perseo.

Asimismo, no se debe perder de vista la conexión quizás más evidente: que la alquimia, en su dimensión más concreta, es la práctica de la transmutación de metales para la obtención de oro y que la escena de la lluvia dorada representa la transubstanciación de Júpiter en este mismo metal. Sin embargo, la alquimia también encierra un aspecto místico y simbólico. En efecto, según el hermetismo, el proceso de transformación hacia el metal más puro representa la transformación del hombre, la búsqueda de la virtud espiritual, del absoluto, de Dios (Chevalier \& Gheerbrant, 1982).

En el propio proceso alquímico se actúa el ciclo de vida, muerte y resurrección, a través de las cuatro etapas que define la gran obra: nigredo, la etapa de putrefacción en la que el hombre va hacia la oscuridad, para luego pasar a la segunda fase; albedo, el blanqueamiento, cuando surge la esencia espiritual; la tercera, citrinitas, el surgir de la luz del sol en el propio ser; y, la cuarta, rubedo, el momento en el que la transmutación es integral, se unen espíritu y materia en un nuevo ser. 
Si la alquimia no es otra cosa que una extensión de la generación natural que transforma la materia, pero también al sujeto, que se disuelve por medio de este proceso en el ser universal, ¿no es el oro -el producto más elevado del proceso alquímico- una sustancia redentora? Al poner en relación el episodio de Dánae y la lluvia dorada con los principios alquímicos, la representación de Goltzius admite una nueva interpretación en la que la joven no es profanada por el vil metal, sino que la presencia del oro propicia su salvación.

En este punto, vale introducir una última referencia. El llamado Libro de Lambspring, un tratado alquímico cuya edición más antigua de la que se tiene conocimiento data del año 1556 [Figura 5]. Una de las versiones fue compilada por Nicolás Barnaud Delphinas, quien fue cercano al grupo de alquimistas de la corte de Rodolfo II. Esta versión fue publicada en Antwerp en 1599 y luego traducida al inglés por Arthur Edward Waite y publicada en Londres en 1893. El tratado, a través de una serie de 15 dibujos alegóricos en la que se identifican distintas etapas alquímicas, exhibe este proceso de transmutación integral, que es material, pero, sobre todo, espiritual.

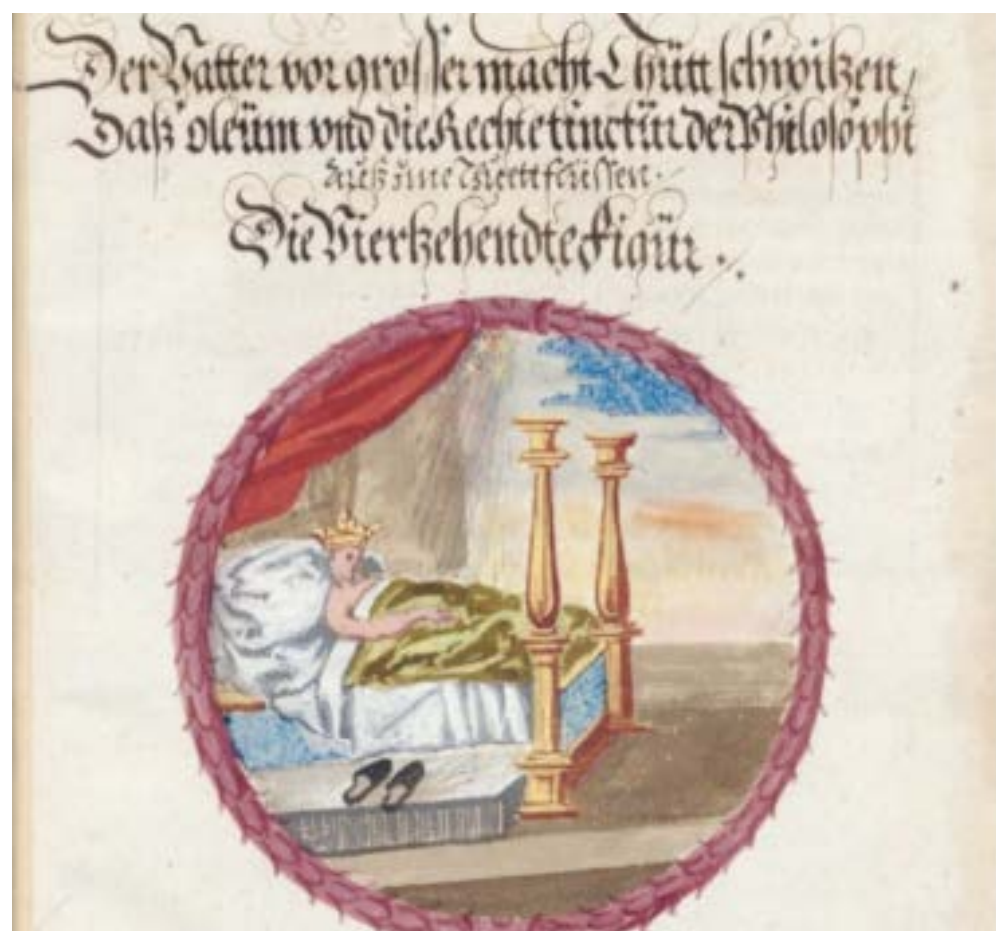

Figura 5. Libro de Lambspring. Manuscrito de 1556. Biblioteca Central de Zúrich, Zúrich 
7 «Here the Father sweats on account of the Son, And earnestly beseeches God, Who has everything in His hands, Who creates, and has created all things, To bring forth his Son from his body, And to restore him to his former life. God hearkens to his prayers, And bids the Father lie down and sleep. Then God sends down rain from heaven. To the earth from the shining stars. It was a fertilizing, silver rain, which bedewed and softened the Father's Body. Succour us, Lord, at the end, That we may obtain Thy gracious Gift!» (Barnaud Delphinas, 1893, p. 302). Itálica y traducción de la autora del artículo.
La anteúltima imagen de la serie muestra a un hombre en su lecho, que recibe una lluvia que cae del cielo e ingresa a la habitación a través de la ventana. En la traducción al inglés de la edición realizada por Barnaud Delphinas (1893), el texto que acompaña el dibujo es el siguiente:

\begin{abstract}
Aquí el Padre suda a causa del Hijo, Y ruega sinceramente a Dios, Quien tiene todo en sus manos, Quien crea, y ha creado todas las cosas, Que extraiga a su Hijo de su cuerpo, Y que lo devuelva a su vida anterior. Dios escucha sus oraciones, $Y$ ordena al padre que se acueste y duerma. Luego, Dios envía lluvia desde el cielo. Hacia la tierra desde las estrellas brillantes. Una lluvia fertilizante y plateada, Que adormeció y ablandó el cuerpo del Padre. ¡Socorranos, Señor, al final, para que obtengamos tu misericordioso don! (p. 302). ${ }^{7}$
\end{abstract}

En las imágenes anteriores se relata la historia de un padre, un hijo y su guía que, según se aclara, corresponden al cuerpo, al espíritu y al alma, respectivamente. El hijo sale a conocer el mundo con su guía. El padre (el cuerpo), alejado de su descendencia (el espíritu), pierde su fuerza. Cuando el hijo retorna, el padre, en un desborde de alegría, se traga a su hijo. La lámina en la cual nos detenemos es aquella en la que se observa al padre sudando en su cama producto del calor que le generó la ingesta, mientras reza para que su hijo vuelva a la vida. Ante estas plegarias, Dios envía una lluvia plateada, desde las estrellas hacia la tierra. Esta tiene un efecto fertilizante: el cuerpo del padre empapado por la llovizna cede y da paso al precioso regalo: el padre revitalizado da luz a un nuevo hijo. El texto agrega que ahora el hijo permanecerá por siempre en el padre y el padre en el hijo.

Esta escena final del tratado alquímico también remite, crípticamente, al episodio de Dánae. Dios provee una lluvia metálica que, en este caso, implica, no solo la concepción de un nuevo hijo, sino también el renacimiento del padre. En el acto de transmutación queda subsumido el ciclo completo: la vida, la muerte y la resurrección. La perspectiva alquímica arroja nueva luz para comprender la escena de Dánae y la lluvia dorada. Dios, transubstanciado en oro, baña a Dánae, como consecuencia, Perseo es concebido a la vez que Dánae resurge. Es Perseo, en definitiva, la razón por la cual Dánae es sustraída de su celda y arrojada al mar, donde otro dios - Poseidón, en este caso-decide su suerte y salva la vida de la madre y del niño para que Dánae, finalmente, pueda vivir su vida. 


\section{Comentarios finales}

Al considerar la frecuencia con la que fue representado el episodio de Dánae y la lluvia dorada entre los siglos XV y XVII no se puede evitar observar las cualidades que lo convierten en un tema atractivo. El erotismo de la escena y la tensión entre las dos interpretaciones polares del mito, entre la prostituta y la virgen, son evidentes. En esta oportunidad, hemos propuesto una nueva fuente de interés en el tema, al destacar un segundo protagonista de la escena: el oro. En definitiva, es el atributo que hace distinguible a este personaje mitológico femenino y al episodio en cuestión. La inquietud que produce el oro en los hombres de la época se hace eco en dos ámbitos de conocimiento que tuvieron un desarrollo significativo durante el período, la ciencia económica y la alquimia. Estas disciplinas han contribuido en los intentos por desentrañar el misterio del oro: ¿cuál es la fuente de su poder?

Al abordar algunas representaciones de Dánae a través de fuentes y elementos de ambos campos, hemos encontrado matices en la manera en la que el oro aparece en la escena. Desde la perspectiva económica, se vuelve a la ya acostumbrada lectura de que el oro es un vil metal que profana la virtud de la joven. Ahora bien, al observar la escena a la luz de ciertos aspectos de la alquimia, se invierte la relación: el oro puede ser visto como un elemento que cataliza un ciclo de resurrección que atraviesa la oscuridad para dar paso al renacimiento físico y espiritual del personaje femenino.

\section{Referencias}

Aldama, C., Benchimol, P., Harracá, M., Navarro, L. y Piqué, P. (2012). Las transformaciones de las representaciones del mundo desde el tránsito de la Edad Media al Capitalismo Comercial como concepto económico. Revista Nueva Economía, 19(35), 13-51.

Apolodoro. [siglo I-II d. C.] (1950). Biblioteca mitológica (Libro II). Ciudad Autónoma de Buenos Aires, Argentina: Facultad de Filosofía y Letras, Universidad de Buenos Aires.

Barnaud Delphinas, N. [1599] (1893). The Book of Lambspring [El libro de Lambspring]. En A. E. Waite (Ed.), The Hermetic Museum, Vol. I [El Museo Hermético, Vol. I] (pp. 271-306). Londres, Reino Unido: J. Elliot \& Co. Recuperado de http://www.sacred-texts.com/ alc/hm1/hm113 
Berger, J. (2000). Modos de ver. Barcelona, España: Gustavo Gili.

Chevalier, J. y Gheerbrant, A. (1982). Dictionnaire des symboles: Mythes, rêves, coutumes, gestes, formes, figures, couleurs, nombres [Diccionario de símbolos: mitos, sueños, costumbres, gestos, formas, figuras, colores, números]. París, Francia: Robert Láffont.

Davanzati, B. [1588] (1803). Lezione delle monete [Lección sobre la moneda]. En Scrittori classici italiani di Economia Politica [Escritores Clásicos Italianos de Economía Política] (Parte Antica, Tomo II) (pp. 19-50). Milán, Italia: G. G. Destefanis.

Goltzius, H. (1603). Dánae durmiente siendo preparada para recibir a Júpiter [Pintura]. Los Ángeles, Estados Unidos: Los Angeles County Museum of Art.

Gossaert, J. (1527). Dánae [Pintura]. Múnich, Alemania: Alte Pinakothek.

Libro de Lambspring [Manuscrito]. (1556). Zúrich, Suiza: Biblioteca Central de Zúrich.

Marshall, P. (2006). The magic circle of Rudolf II. Alchemy and astrology in Renaissance Prague [El círculo mágico de Rodolfo II. Alquimia y astrología en la Praga Renacimental]. Londres, Reino Unido: Bloomsbury.

Marx, K. [1867] (2011). El capital. Ciudad Autónoma de Buenos Aires, Argentina: Siglo Veintiuno.

Melion, W. S. (1992). Shaping the Netherlandish canon: Karel Van Mender Schilder - Boeck [Dando forma al canon holandés: Schilder Boeck de Karel van Mender]. Chicago, Estados Unidos: University of Chicago Press.

Millner Kahr, M. (1978). Danaë: Virtous, voluptuous, venal woman [Dánae: Mujer virtuosa, voluptuosa, venal]. The Art Bulletin, 1(60), 43-55.

Ovidio Nasón, P. [8 d. C.] (2012). Las metamorfosis. Madrid, España: Gredos. 
Piqué, P., Navarro, L., Harracá, M., Benchimol, P. y Aldama, C. (2018). Investigación sobre la transición entre las doctrinas mercantilistas y el nacimiento de la Economía Política. Un análisis de los aportes de Thomas Mun, James Steuart y David Hume. Revista Civilizar Ciencias Sociales y Humanas, (32), 119-132. Recuperado de https:// ri.conicet.gov.ar/handle/11336/76427

Pirenne, H. [1926] (2011). Las ciudades de la Edad Media. Ciudad Autónoma de Buenos Aires, Argentina: Claridad.

Romero, J. L. [1987] (2010). Estudio de la mentalidad burguesa. Ciudad Autónoma de Buenos Aires, Argentina: Alianza Editorial.

Rubin, I. I. [1929] (1989). A History of Economic Thought [Historia del Pensamiento Económico]. Londres, Reino Unido: Pluto Press.

Santore, C. (1991). The Renaissance Courtesan's Alter Ego [El Alter Ego de la cortesana del Renacimiento]. Zeitschrift für kunstgeschichte, 54(3), 412-427.

Seaford, R. (2004). Money and the early Greek mind. Homer, philosophy, tragedy [El dinero y la mentalidad griega temprana. Homero, filosofía, tragedia]. Nueva York, Estados Unidos: Cambridge University Press.

Sluijter, E. J. (1999). Emulating sensual beauty: Representations of Danaë from Gossaert to Rembrandt [Emulando la belleza sensual: Representaciones de Dánae, desde Gossaert hasta Rembrandt]. Simiolus: Netherlands Quarterly for the History of Art, 27(1/2), 4-45.

Smith, A. [1776] (1999). The Wealth of Nations [La Riqueza de las Naciones]. Londres, Reino Unido: Penguin Books.

Suyderhoef, J. (1649). Retrato de Hendrik Goltzius [Grabado]. Róterdam, Países Bajos: Museo Boymans van Beuningen.

Vecellio, T. (1553). Dánae [Pintura]. Londres, Inglaterra: Apsley House.

Zlatohlávková, E. (2017). Spranger or Goltzius? Preparatory studies for the cycle Creation [¿Spranger o Goltzius? Estudios preparatorios para el ciclo Creación]. Ars linearis, (7), 120-123. 